\title{
The task-driven teaching of Java program design
}

\author{
Zhan Zhenzhong ${ }^{1}$, Mu Zhendong ${ }^{2}$ \\ 1College of Continuing Education, JiangXi University of Technology, Jiangxi Nanchang 330098 \\ 2College of Information Engineering, Jiangxi College of Technology, Jiangxi Nanchang 330098
}

Keywords: Task-driven teaching; Java program; Self-learning

\begin{abstract}
Java programming is a lot of colleges and universities have set up a computer programming language courses, programming capability is a measure of the level of expertise of a computer, Java language is a tool to measure the ability of how to improve students' ability to grasp the Java language is a lot of a subject teacher research paper task-driven approach to an object, the task-driven teaching how to introduce Java programming course.
\end{abstract}

\section{Introduction}

The so-called "mission-driven" is the information technology in the learning process, students in teacher's help, tightly around a common task activity center, in a strong motivation problem, driven by the positive application of active learning resources, conduct self-exploration and interactive collaborative learning, and at the same time to perform a given task, and guide students to produce a study and practice. "Task" is a build in constructivist teaching pedagogy based on the theory. It requires the creation of "mission" goals and teaching situations. Students with authentic learning tasks in the exploration. In this process, students will continue to get a sense of accomplishment, you can more greatly stimulate their desire for knowledge, and gradually form a perception of mental activity virtuous cycle, in order to cultivate the independent exploration and development ahead of self-learning ability.

"Task-driven approach" is an established methodology in the constructivist learning theory on the basis of it in the past in order to impart knowledge-based traditional teaching philosophy, changed to solve the problem, task-based multi-dimensional interactive teaching philosophy; reproduction into teaching inquiry-based learning, so that students in active learning state, every student based on their current understanding of the issues, the use of knowledge and their own unique experiences shared a proposal to solve the problem.

\section{Java education problems}

Java programs have an increasingly important role in schools at all levels of education, which is characterized by strong practical knowledge update speed, which requires teachers to pay special attention to the students' problem-solving training and learning abilities. Java programs distributed knowledge often is network-based, rather than linear. Use Java to solve a practical problem, often involving multiple knowledge points. Therefore, there is no need Java teaching strictly in accordance with a linear manner, you can start from different points according to the characteristics of the content, while students are able to make comprehensive use of knowledge. 
However, the traditional computer language teaching attaches great importance to the "knowledge" to build a body of knowledge, emphasis on "progressive" teaching model, emphasizing basic concepts of fixed pattern memorizing and operations. An array of teaching in the Java language, for example, the usual method of teaching is the teacher of all the arrays define methods and initialization methods to the students, and even the definition of the two formats to the students, it looks to the students a lot of ways, a lot of knowledge, in fact, very confused students learn, not to teach a method as more suitable.

As can be seen, the traditional computer language teaching is an alternative teaching strategies, student teachers alternative information processing, fewer students are engaged in intellectual activity and practical activities, easy to produce psychological dependence on teacher cognition. This teaching method has the following disadvantages:

1 , teacher-centered, student passively accept knowledge, ignoring the initiative and creativity of students.

2, according to the knowledge of the inherent logical order, the individual knowledge scattered to explain, one-sided pursuit of the integrity of knowledge, teaching content and messy abstract, students tend to lose interest in learning, I do not know how to use these comprehensive knowledge points.

3, emphasis on students' skills, ignoring the student's ability. This approach allows students to quickly grasp the software operation, so many teachers are respected. However, it is more like a "Software Guide" style of teaching. Students in the "hands-on" teaching process, mechanical imitation of every operation, almost no brains. Over time, the students have a great dependence on teachers, a problem encountered said: / This content teacher has not speaking, I will not.

Bloom's famous educational theorists believe that simply to impart knowledge and acceptance for the purpose of teaching the abilities of students to ignore the low level of education. Demand for computer courses and social characteristics of new talent, and requires us to strive to develop students' problem solving skills, communication and cooperation, learning ability, and information literacy. To this end, we have adopted a task-driven teaching shortcoming to overcome conventional teaching methods in Computer Teaching.

\section{Java task-driven teaching}

1, well-designed task is critical to effective teaching task-driven. Teachers should be reasonable grasp the depth and breadth of teaching content, seriously consider the initial capacity and the general characteristics of the students, to break the logical order of knowledge itself, will be integrated into a multiple knowledge authenticity, feasibility, level, integrated and open tasks. For example, in the use of the Java language for database programming, just tell the students how to use SQL to connect to the database class does not need to explain in detail the meaning, does not require a database connection for each method are explained in detail, just talk about how to connect to SQL2000 to other methods in passing. The task is simple to students how to use Java for database search, delete and other basic functions. Then, around the task, the students focused on the design of self-learning situations, learning support factors (such as support for the learning environment, collaborative learning, learning resources, etc.) and the learning evaluation activities. Finally, teachers can play the role of the student to complete the task. On the one hand, which is conducive to the discovery task design problems, on the other hand, teachers can create an instance of the task of assigning tasks for subsequent stages. 
2 , the teacher let the students a clear mission objective, requirements, procedures and evaluation methods, understanding necessary to complete the task of learning conditions and learning resources. Teachers should by various means, such as the creation of scenarios to demonstrate the task instance or group competitions, to mobilize students' interest and participation in the initiative to guide students to discover the problem.

3, students after a clear mandate by independent learning essential new knowledge, and research activities between teachers and students or between students, to explore ways and means to complete the task. Teachers should be targeted to guide students' thinking, to grasp the learning situation, timely coaching, play teachers / leading role.

4 , teachers should organize students to complete the task in the process and the results are summarized, summary and evaluation of knowledge summarize leak filled demonstration on the part of the difficulties that poor learning ability of students to keep up with the progress of teaching. To focus on learning methods and evaluation of the learning process, encouraging the implementation of the evaluation, but pay attention to encourage students' creative thinking and encourage student achievement. If the teacher is just their personal authority, by virtue of their experience in the evaluation of students, often unfair, easy to dampen the enthusiasm of the students. Therefore, the evaluation methods should be flexibility to use personal self-assessment, peer assessment within the group, between the two groups in the form of a variety of evaluation and peer review comments and other teachers.

\section{Teaching experience}

Constructivist instructional design principles emphasize: student learning activities must be combined with a task or problem; to explore the issues to guide and sustain learners' interest and motivation; create realistic teaching environment for students with authentic learning tasks; students must have learning initiative, teachers should encourage students to continue to move forward.

Task-driven method is an established methodology in teaching based on the theory of constructivism is a teaching method to implement inquiry-based teaching model. From the student's point of view, it is a learning method. Task-driven teaching is not based on behavioral learning theory, where the task is different from behaviorism to promote skills practice, it is the power drive student learning, rather than the ultimate goal of teaching. The final aim is to enable students to acquire teaching skills and knowledge through the task, learning to learn, develop skills.

Teaching experience shows that task-driven teaching has obvious advantages. Through the integration of the real mission of teaching, student learning objectives clear, problem-solving process is a learning process, to cultivate students' cognitive strategies, training students' resilience and ability to innovate, develop their indomitable spirit of exploration and psychological qualities. When a large task, task-driven teaching often takes the form of teaching organization group, as a member of the group of students will gradually learn how to divide and assign tasks, how to express their views, how to coordinate with other team members, which will help to improve students' communication skills and ability to cooperate.

If a student is having problems, try not to answer directly to tell him, but managed to guide students to find their own solutions to improve his ability to learn. For example, using Java network programming, I give students the task is modeled a chat tool, but then the students did not know how to get involved, I just tell them how to use the "socket", and then put them into groups, and ultimately on their own complete the task. 


\section{Acknowledgements}

This work was financially supported by project of Technology Department of Jiangxi Province [No 2013BBE50051].

\section{References}

[1]Weizheng S, Hongmin S, Xihai Z. Exploration and Practice of the Task-driven Teaching Mode in the Teaching of Computer Course $[\mathrm{J}][\mathrm{J}]$. Journal of Northeast Agricultural University (Social Science Edition), 2007, 1: 035.

[2]Hui-min W U Q Z. Exploration and Practice of Task-driven in the Teaching of Electronic Technology [J][J]. Journal of Changzhou Vocational College of Information Technology, 2008, 6: 015.

[3]Samuda V. Guiding relationships between form and meaning during task performance: The role of the teacher[J]. Researching pedagogic tasks: Second language learning, teaching and testing, 2001: 119-140.

[4]ZHANG S, WANG G. Research of Case-task Driven Mode in Teaching of Computer Programming Language[J]. Computer, 2010, 2: 038. 